\title{
Gay bear subculture: self-concepts, subjective practices and mental health
}

\author{
Subcultura gay bear: auto-conceitos, práticas subjetivas
}

e saúde mental

\section{Dilcio Dantas Guedes'}

'D.E.A en Psycholgie du Développement. MSc in Psychology. Toronto, Canada. dilcio@gmail.com

Resumo | Este artigo explora o ponto de vista sugerido de que indivíduos que se identificam com a subcultura "urso" entre homens gays apresentam autoconceitos e práticas subjetivas associadas à masculinidade hegemônica e atitudes negativas em relação à efeminidade, o que pode afetar sua saúde sexual e mental. Para explorar esta sugestão, articulou-se uma análise sócio-histórica sobre os relacionamentos homoafetivos e o fenômeno da subcultura dos gays ursos. Através desta exploração, verificou-se, por um lado, que esses indivíduos envolveram-se em diferentes formas de grupos formados com 0 intuito de mitigar a marginalização dentro da comunidade LGBT, enfatizando a camaradagem, o carinho interpessoal, a aceitação da maturidade e da estética da classe trabalhadora como elementos de suas identidades. Por outro lado, também foram identificadas referências atributivas heterossexistas implícitas no discurso e nas práticas desses indivíduos. A revisão de uma amostra da literatura revisada e publicada na última década apontou que esses indivíduos apresentaram comportamentos idiossincráticos influenciados por fatores socioculturais e éticos, mas que convergiram em elementos da masculinidade hegemônica. Como parece que essa convergência pode afetar a saúde sexual e mental desses homens, profissionais de saúde mental podem beneficiar-se com a compreensão das especificidades das necessidades dessa população. Outros estudos empíricos são sugeridos para verificar tais associações em contextos socioeconômicos-culturais, étnicos e de orientação sexual mais diversos.

Palavras-Chave: Homossexualidade, Subjetividade, Masculinidade.

\begin{abstract}
I This paper explores the suggested standpoint that individuals who self-identify as part of the "bear" subculture among gay men present self-concepts and subjective practices associated with hegemonic masculinity and negative attitudes toward effeminacy which might be impacting their sexual and mental health. To explore this suggestion, a socio-historical analysis about the homoaffective relationships and the gay bear phenomenon was articulated. Through this exploration, it was verified, on one hand, that these individuals engaged in different forms of peer crowds that were formed to attempt to mitigate the experience of being outcast within the gay mainstream, emphasizing the camaraderie, the interpersonal affection, the acceptance of maturation, and the working-class aesthetic as elements of their identities. On the other hand, references of implicit heterosexist attitudes in the discourse and practices of these individuals could be also identified. The review of a sample of the last decade peer-reviewed published literature pointed out that these individuals engaged in idiosyncratic behaviours that were socio-cultural and ethically influenced, but converged towards elements of the hegemonic masculinity. It seems that this convergence might be impacting on the sexual and mental health of the self-identified bear gay men. Mental health professionals could benefit in understanding the specificities of these population's needs. Further empirical studies are suggested in order to verify these associations in more diverse socio-economic-cultural, ethnic, and sexual orientation contexts.
\end{abstract}

Key-Words: Homosexuality, Subjectivity, Masculinity. 


\section{Introdução}

Este estudo exploratório e bibliográfico articula a constituição do nicho da subcultura ursina e a subjetividade de seus membros através de um quadro sócio-histórico, descrevendo uma breve história sobre como as relaçõeshomoeróticas e homoafetivas - referentes ao erotismo e vínculo afetivo entre indivíduos do mesmo gênero - em diferentes contextos socioculturais influenciaram a construção e ○ uso da ideologia sexual hegemônica para regular os comportamentos das minorias relacionadas à orientação sexual.

O contexto psicossocial foi usado como base para a compreensão da comunidade dos ursos homossexuais, seus conceitos sobre si e suas subjetividades. Acreditase que esta revisão seja relevante porque procura entender uma nova realidade masculina presente nas relações interpessoais dos ursos gays. Além disso, porque busca a amplificação do discurso sobre práticas afirmativas no campo da saúde mental em relação às microculturas da comunidade LGBTQ (Lesbiana, Gay, Bissexual, Transgênera, Queer), que, neste estudo, está focada na compreensão de práticas subjetivas da masculinidade, das necessidades singulares e dos fatores internos e externos que podem afetar - bem-estar psicológico desses homens gays que se identificam como ursos.

\section{Breve revisão histórica do homoerotismo e homoafetividade entre os homens}

Enquanto $\circ$ homoerotismo masculino se refere à qualidade não estática associada à atração sexual e à sua expressão entre indivíduos do mesmo gênero, a homoafetividade relaciona-se com qualquer tipo de vínculo entre esses indivíduos, independentemente da sua orientação sexual (Costa, 1992). As representações simbólicas da homoafetividade e homoerotismo podem ser resgatadas em diferentes períodos da história humana.

Por exemplo, no antigo Egito e na Mesopotâmia, as relações afetivas e as relações sexuais entre os homens foram praticadas, mas apenas socialmente aceitas em eventos místicos e rituais ou se relacionadas à amizade e lealdade entre guerreiros. No entanto, um homem ser penetrado no ânus por outro homem era considerado um crime punível (Parkinson, 1995; Montserrat,
1996; George, 1999). Essas práticas certamente influenciaram as leis de outros povos da região, como os hititas e os hebreus (Bottero, 2001). Há referências sobre essas práticas entre os cananeus: "Não as repitam [referindo-se a práticas de sexo] como é feito no Egito, onde viveram, ou como é feito na terra de Canaã, onde eu vos conduzo. Não sigam suas práticas." (18, 3). Referências na Bíblia (1 Reis 14: 23-24, 2 Reis 23: 4-7) também sugerem essa afirmação. Grande parte da literatura indica que, para os hebreus, a prática sexual entre pessoas do mesmo sexo era condenável, como se afirma em Levítico: "Não se deitará com um homem como mulher: é abominação (18: 22) [...] serão mortos, o seu sangue estará sobre eles" (20:13).

Na Grécia antiga e no Império Romano o homoerotismo e a homoafetividade entre um adulto e um jovem entrelaçaram-se com atividades sexuais, como um mecanismo de educação moral e cívica, e porque remetia à busca da estética do Belo (Foucault, 1976, 1984). No entanto, não era aceita a penetração do ânus, a prática da felação ou o anilingus entre os cidadãos, enquanto a amizade "íntima" entre os soldados era convencionalmente vista como um sinal de grande virilidade e honra (Hubbard, 2003).

Na China antiga há registros de comportamentos homoeróticos entre homens em algumas casas de chá em Pequim, dedicadas a encontros homoafetivos e sexuais durante a dinastia Qing (Hinsch, 2005). Entre os hindus na Índia antiga, as práticas homoeróticas não eram consideradas inferiores ou vergonhosas, mas, de acordo com o princípio hindu da castidade, acreditavase que, se um homem penetrasse o ânus ou a boca de outro homem, punições deveriam ser infligidas (Vanita \& Kidwai, 2000; Pattanaik, 2002).

As antigas sociedades árabes também praticaram pederastia, e a atividade homoafetiva era moderadamente exposta (Colligan, 2003). Neste contexto, a relação sexual entre indivíduos do mesmo sexo era relacionada a atos de dominação e subjugação do outro (aqueles que eram penetrados eram desonrados). Assim, a masculinidade daquele que penetrou não era questionada (El-Rouayheb, 2005). Com o advento do cristianismo, os romanos e seus povos conquistados foram obrigados a seguir as doutrinas que eram consideradas práticas pagãs, politeísmo, a exacerbação das práticas sexuais e a ostentação. A castidade foi disseminada através 
dos antigos povos ocidentais, especialmente após o surgimento do imperador Constantino (323 A.C). Assim, à medida que o cristianismo se propagava, a relação sexual não deveria ocorrer para o prazer sexual, pois a procriação era o objetivo final. Nesta perspectiva, 0 homoerismo era punido com a morte (Murstein, 1974).

Os registros sobre o homoerismo na Idade Média são raros. Alguns autores sugerem que os gregos continuaram a praticar a pederastia e que 0 homoerotismo também ocorreu durante o domínio bizantino. $O$ termo usado para designar práticas homoeróticas na Idade Média foi o "sodomia" e foi originalmente usado pelos primeiros cristãos. Documentos históricos indicaram que este conceito apareceu entre os cristãos latinos em 1175 , na Península lbérica, e estava relacionado à invasão otomana, cujos hábitos de homosociabilidade foram conhecidos como comportamentos aberrantes pelos primeiros cristãos - que interpretaram suas manifestações homosociais como pecados e usaram esses atos como ferramentas para propagar estereótipos e promover discriminação. Neste momento, o homoerismo foi considerado peccatum contra naturam (pecado contra a natureza), portanto um ato demoníaco. No entanto, alguns registros históricos indicaram que não era incomum que monges buscassem encontros sexuais. Com o papa Gregório VII, o celibato foi introduzido e, com isso, a perseguição dos islâmicos, judeus, hereges e sodomitas (Ranke-Heinemann, 1991).

Enquanto as atividades homoeróticas permaneceram no obscurantismo durante esse período, as noções de amor romântico começaram a florescer sob a base do protótipo de uma ideologia sexual hegemônica - a marca da Era Moderna. Esta ideologia é notoriamente circunscrita pela premissa da monogamia, do patriarcalismo e do heterossexualismo, onde a sexualidade dos indivíduos deveria ser regulada - em nome do bem-estar dos indivíduos (Foucault, 1976, 1984). Neste contexto, as práticas homoeróticas foram marginalizadas e praticadas em espaços ocultos, formando subculturas (Giddens, 1993).

Durante o século XIX, embora a ideologia sexual hegemônica não tivesse sido desafiada, eventos sociais importantes culminaram em um processo de mudança, no qual o conceito tradicional de família foi questionado. Por exemplo, após as grandes guerras, a intensificação da industrialização gerou migração maciça de áreas rurais para áreas urbanas, permitindo que homens e mulheres desenvolvessem novos estilos de vida, criando novas áreas de socialização e experimentando outras formas de sexualidade (Kinsman, 1996), estabelecendo um círculo vicioso: o Estado reprimia indivíduos que demonstraram práticas sexuais e expressões de gênero não aceitas, mas também abriram lacunas marginalizadas no espaço social que permitiam que esses indivíduos se congregassem, socializassem e expressassem seu homoerotismo. A fim de estabelecer controle repressivo, os guardiões das normas morais identificariam indivíduos "desviantes" através de estereótipos associados ao homossexualismo da época, como a efeminidade, o travestimo e o traje masculino vitoriano clássico.

$\mathrm{Na}$ verdade, essas características compuseram as representações sociais da homossexualidade e algumas de suas subculturas em diferentes sociedades ocidentais. Por exemplo, Tamagne (2000) afirmou que, durante a década de 1920, houve um culto ao homossexualismo na Europa. Durante esse período, na Holanda e na Alemanha, houve também uma cena política homossexual aberta. Na verdade, a primeira organização homófila era holandesa. Enquanto na Alemanha a subcultura homossexual era mais esquerdista, na Inglaterra estava mais associada à aristocracia dos círculos acadêmicos, sendo punível com prisão. Na França, desde a Revolução Francesa, o código criminal de 1791 já não reconhecia a "sodomia" como crime. Na Espanha, embora o crime de sodomia tenha sido abolido em 1822, "los violetas" (termo pejorativo relacionado aos homossexuais) foram fortemente reprimidos. Em Portugal, aqueles que eram identificados como homossexuais eram enviados para Mithras - instituições de reabilitação que funcionavam como prisões (Bastos, 1997). $\mathrm{Na}$ Itália, embora as leis contra as relações homossexuais estivessem abolidas em 1890, ocorreu uma repressão semelhante, especialmente no regime de Mussolini (Dall'Orto, 2015) e, na América Latina, também exerceu-se repressão semelhante (Mott, 2011).

Embora ○ fenômeno do homoerismo e da homoafetividade tenha florecido nos centros urbanos, era, predominantemente, uma prática aristocrática urbana. No entanto, durante a década de 1930, o cenário mudou devido ao clima sociopolítico que promoveu a Segunda Guerra Mundial. Na Alemanha, a nova ideologia nacionalista reprimiu fortemente 
aqueles identificados como homossexuais por meio do trabalho forçado ou da morte. Os jovens eram encorajados a seguirem regras que sustentavam 0 projeto eugênico de pureza ariana, visando destruír - "germe da homossexualidade" (Pretzel \& Rossbach, 2000; Hoffschildt, 1999).

Nos Estados Unidos e no Canadá, as práticas homoeróticas foram consideradas crime ao mesmo tempo em que as subculturas também foram estabelecidas: as fadas (homossexuais afeminados) e os lobos (homossexuais masculinos) originaram-se em Nova York e, mais tarde, em meados dos anos 1950, a subcultura dos Leathermen surgiu em Nova York, Los Angeles e Chicago (Chauncey, 1994; Rubin, 2004).

Este contexto na América do Norte promoveu outros fenômenos sociais que afetaram profundamente a tensão entre a ideologia sexual hegemônica e aqueles que não se adaptaram a ela: o movimento dos direitos afro-americanos nos Estados Unidos, o movimento de contracultura dos anos 1960, o movimento contra à guerra do Vietnã e, finalmente, os movimentos homofílicos e homossexuais como formação da Frente de Libertação Gay, que fometaram uma intolerância crescente à repressão policial (Edsall, 2003). Esses movimentos envolveram ativistas do movimento Black Power, do movimento feminista e do movimento antiGuerra do Vietnã, e várias organizações LGBT (incluindo os membros do movimento Urso), reforçando uma frente em defesa da igualdade e do fim da discriminação com base na orientação sexual. No entanto, em vários Estados dos Estados Unidos, especialmente na Califórnia, a homossexualidade era considerada um crime punível com prisão, castração, até mesmo tratamento com eletrochoque e lobotomia (Carter, 2004).

Em síntese, as referências históricas sobre a regulação e repressão das práticas homoeróticas, a ênfase em uma masculinidade hegemônica e heterosexista, os efeitos pós-guerra, como a migração das áreas rurais para os centros urbanos, a redefinição dos espaços de homosocialização e homoerótica, a opressão do Estado extensiva sobre as práticas sexuais não conformes, os movimentos sociais que reivindicaram os direitos civis, a igualdade de gênero, 0 fim da discriminação baseada na orientação sexual e na raça, os movimentos contraculturais e a influência das ideologias sociopolíticas, influenciaram a forma como as práticas societárias regulamentavam a expressão de homoaffectividade e homoerotismo. Tais práticas foram operadas através de mecanismos persistentes e perpetuadas por diferentes instituições sociais ao longo da vida do indivíduo - gerando um efeito deletério na saúde mental de muitos daqueles que não estavam de acordo com a ideologia sexual dominante.

\section{A ideologia sexual hegemônica e o estresse minoritário}

Ao longo da história, houve uma construção elaborada de uma representação estigmatizada de indivíduos cujas práticas sexuais eram não conformes, que justificava a regulação de seus comportamentos. Esta representação foi fundada em uma ideologia sexual dominante, pela qual tem predominado a hegmonia masculina heterossexual. $O$ impacto imediato dessa configuração na comunidade gay foi a internalização de mecanismos de controle, como sinais e discursos que se traduziram em estigmatização e exclusão, gerando a exposição excessiva a estressores relacionados à orientação sexual (Meyer, 2003). Exemplos desses mecanismos são eventos cumulativos, crônicos, repetidos e antecipados de estressores, como indignações verbais, comportamentais ou ambientais diárias (como assédios heterosexistas), que comunicam atos de humilhação e micro-agressões veladas ou abertas, como atos de discriminação sistêmica.

Estudos demonstraram que esses mecanismos produzem um efeito prejudicial composto em membros de diferentes grupos dentro da comunidade LGBTQ, geralmente relacionados à rejeição de famílias e pares, exclusão religiosa, trabalho e discriminação cotidiana que, juntos, geram processos psicológicos como sensibilidade à rejeição, homofobia internalizada, e a necessidade de ocultação pessoal e interpessoal. As consequências desses processos são a constituição de fatores de risco que afetam a saúde mental desses indivíduos (Meyer, 2003; Hatzenbuehler, 2009).

Entre muitos fatores de risco podem ser destacados regulação afetiva precária, ruminação sobre o sofrimento, a desregulação emocional, a falta de apoio social, a falta de assertividade, a baixa autoestima geral e sexual, a depressão, a ansiedade, a maior propensão ao consumo de álcool e substâncias, sexo anal sem camisinha, violência com o parceiro e suicídio (Hatzenbuehler, 2009; Tulloch et al., 2015; Eldalhan 
et al., 2015). Como seria de esperar, muitos aspectos constitutivos da subjetividade, identidade, autoconceito LGBTQ, bem como suas práticas subjetivas, saúde e bem-estar social, seriam influenciados por esses estressores e seus processos psicológicos, dos quais a masculinidade hegemônica e heterosexista perpetra na vida desses indivíduos. É possível verificar como esta ideologia impôs suas premissas e influenciou o aumento da subcultura Bear.

\section{Contexto histórico para o surgimento do fenômeno ursino na comunidade gay}

O trabalho organizado por Wright (1997) sobre o início e a perpetuação do fenômeno ursino indicou que suas raízes remontam ao movimento Leatherman em meados da década de 1950 e à cultura Girth and Rirth na década de 1970.

A subcultura de Leatherman foi formada por um grupo composto, inicialmente, por alguns dos veteranos da Segunda Guerra Mundial, conduzidos por valores militares como disciplina e hierarquia, mas também camaradagem, tendo um interesse comum em motocicletas. A estética deste grupo era contornada por códigos hipermasculinos, como musculatura, pelo corporal (incluindo facial), vestuário de couro e a expressão exagerada da masculinidade hegemônica (por exemplo, relação dominação-submissão).

Esses códigos e práticas subjetivas foram traduzidos através da oposição ao estereótipo feminino entre a maioria dos atores sociais da comunidade gay. Paralelamente, houve a influência da cultura Girth e Mirth. Essa cultura refere-se a um clube conhecido dedicado aos homens homossexuais, cuja aparência física era grande e pesada (ou para os homens "gordos" e "amantes dos gordos"). Ambas as culturas foram formadas como uma tendência contrária dentro da cultura gay que enfatizava a juventude, a magreza e a musculatura como as características homoeróticas desejáveis (Suresha, 2002).

Ainda de acordo com Wright (1997), as primeiras referências ao termo "urso" também podem ser rastreadas para um grupo informal de homens no Texas que se identificaram como "amantes dos papais ursos", mas foi em São Francisco que esse termo se tornou mais popular, especialmente durante a epidemia de AIDS na década de 1980. Durante esse tempo, os homens homossexuais que se auto-identificaram como ursos só tiham acesso aos espaços dos Leatherman para a socialização e, devido ao forte impacto da AIDS neste grupo, este acesso tornou-se mais difícil. Essa dificuldade levou esses homens a dispersarem-se e formarem grupos de comunidades, que eventualmente aglutinaram-se, graças aos avanços em tecnologia (por exemplo, pelos avisos enviados pela internet) que permitiu que esses indivíduos se comunicassem de forma mais eficaz e organizassem reuniões cada vez maiores.

Neste ponto, a representação do urso gay associa-se a uma clara oposição aos estereótipos hegemônicos da cultura gay dominante. A pressão dos pares da comunidade gay engedrou uma nova forma de socialização que se formou com um novo autoconceito do homem gay que recusou algumas das práticas dos Leathermen. Uma das suas práticas subjetivas estava relacionada ao uso de lenços. Em vez de usar lenços coloridos para sinalizar preferências para práticas sexuais específicas, os ursos exibiram os ursos de pelúcia como a representação totémica de uma agressividade natural, mas de uma natureza afetiva pautada em intimidade emocional e expressada, por exemplo, com abraços afetuosos.

Em síntese, a identidade do gay urso seria associada a uma alusão exagerada aos ideais de masculinidade (masculinidade natural e masculinidade não objetivada), ao mesmo tempo em que se engajariam em comportamentos homoafetivos. Como tal, este movimento também estava aberto a outras subculturas diferentes, igualmente afetadas pela cultura gay predominante, como os "gordos" (não necessariamente parrudos e peludos) e os "caçadores" (homens mais magros que se atraem por ursos e homens gordos), idosos e outros admiradores que não se identificam como ursos. A partir desta perspectiva, a essência da representação do urso dependeria, no entanto, de uma geometria ideal através da qual o corpo dos indivíduos era demarcado pelo corpo parrudo e pelos corporais, por onde as coxas grossas e tonificadas, as pernas e panturrilhas, braços, costas e peitoral eram enfatizados. A ironia infeliz da erupção dessa comunidade nos anos 1980, no entanto, é que, enquanto suas características contrastavam com o declínio físico com perda de peso e massa muscular retratada através das representações sociais da AIDS (Hennen, 2005), a literatura atual indica que os 
homens homossexuais ursos tendem a se engajar em comportamentos sexuais de alto risco (Willoughby et al., 2008; Moskowitz et al., 2013; Noor, 2017).

Nesse sentido, Sáez (2005) analisou como a representação da masculinidade dentro da comunidade gay produziu um efeito paradoxal sobre a forma como seus símbolos e narrativas constituíam a comunidade ursa e sua dinâmica de poder. Segundo o autor, quando a cultura do Leathermen surgiu na América do Norte durante o cenário homossexual do início dos anos 1950, suas representações e práticas simbólicas foram associadas a uma negação do estereótipo efeminado da população homossexual em geral. Nesse contexto, os sinais de identidade da comunidade gay dos Leathermen pareceu ter convergido os sinais de identidade da comunidade dos ursos: constituição do corpo, integração nos espaços sociais e ênfase na expressão de uma masculinidade mais "natural" - que, supostamente, eram menos exacerbados do que a expressão de masculinidade retratada pelos membros de Leatherman e, paradoxalmente, mais parecida com a representação do vaqueiro americano.

Paradoxalmente também pode-se concordar que a estética do urso parece mais próxima da representação da classe trabalhadora branca heterossexual e urbana, executada por comportamentos que desconsideram a delicadeza, qualquer preocupação com a aparência física e por expressões corporais mais rígidas em movimento, bem como o tom de voz mais baixo ("fala grossa"). Embora igualmente influenciado pelos movimentos dos direitos civis e pelas atividades do grupo de Libertação Gay, as raízes da representação dos ursos homossexuais expressaram uma resposta a uma marginalização interna da subcultura hegemônica (Manley, Levitt \& Mosher, 2007).

\section{O autoconceito e a subjetividade do urso gay}

O conceito de Eu está na idéia de que os significados pessoais e coletivos sobre $\circ$ si são construídos interpersonalmente. Com base nisso, vários autores sugeriram que a subjetividade é uma construção de representações de si e a organização dessas representações dar-se-ia a partir de experiências cotidianas (Guattari, 1999). A subjetividade implica a existência de uma atividade auto-reflexiva a partir da qual a pessoa constantemente produz conhecimento de si própria. Portanto, não é um retrato da identidade, nem é derivada do alcance de uma sensação de interioridade: a subjetividade situa a pessoa em relação às relações socioculturais, como as relações de poder, as convenções sociais, as leis, a economia, a religião e outras instituições (Berlinck, 2010).

Pela perspectiva sócio-histórica de Vygotsky (1929/2000), é possível entender que a composição subjetiva do homem gay que se identifica como urso desenvolve-se, em primeiro lugar, dentro de um contexto social através da interação com outros homens gays que se identificam como ursos. Mais tarde, parece que esta maquiagem é internalizada psicologicamente para, finalmente, articular as outras funções psicológicas superiores já estabelecidas. Nesse sentido, 0 indivíduo opera um sistema de funções dinâmicas, dialéticas, multifacetadas e dialógicas.

Esses papéis podem ser permutados em infinitas possibilidades de expressão, mas são sempre permeados por um viés sociocultural específico. Este viés reconhece $\circ$ indivíduo do gay urso como um ator social que integra $o$ nicho do grupo social que é formado por homens gays que se identificam como ursos, influenciando e sendo influenciado pela pressão coletiva dentro desse contexto social que por sua vez é mantido por essa pressão. Portanto, embora cada indivíduo desse grupo desenvolva papéis sociais únicos, ideias, sentimentos e paixões - o que só pode ser entendido através de sua narrativa sobre seu eu idiossincrático -, está sempre contornado pela geometria do corpo do urso e sua representação da masculinidade, de acordo com o que define a masculinidade em seu contexto sociocultural. Uma ilustração desta tese é apresentada em uma amostra da última década de estudos revisados por pares sobre a comunidade de ursos gays em alguns países diferentes.

Hennen (2005), por exemplo, realizou um estudo etnográfico de 23 homens gays ursos americanos que viviam em um centro urbano. Ele verificou que a narrativa de seus participantes buscava minimizar a diferença entre caracterizar elementos que definiam a heterossexualidade e masculinidades em duas polaridades: de um lado, a ênfase na experiência de afeto e carinho; e do outro lado, a percepção de corpos feminizados como tendo um status inferior. Além disso, ele verificou que a cultura sexual de seus participantes parecia ser influenciada e pressionada pela masculinidade hegemônica. 
No estudo realizado por Manley, Levitt e Mosher (2007) com seis americanos com uma idade média de 41 anos, os significados dos participantes sobre serem gay ursos também convergiram, assim como os participantes de Hennen, para a representação de autoaceitação relacionada à busca de uma estética masculina. Paradoxalmente, enquanto seus resultados indicaram relativo acordo sobre a ideia de que essa estética facilitava a inserção camuflada na esfera heterosexual masculina, todos os participantes aceitaram que a aparência física do gay urso, simbolizada pela masculinidade, a virilidade, o pelo facial e o corpo parrudo e peludo, fossem os principais identificadores do membro da comunidade ursina. No entanto, tal comunidade seria considerada mais aberta a diferentes formas de homoerotismo, de relacionamentos românticos (de monogâmicos a poliamorosos) e à inclusão de homens mais maduros.

Essa inclusão também foi identificada como um elemento crucial para o desenvolvimento de uma maior autoestima entre os gays ursos que estavam obesos. Em um estudo qualitativo com nove homens brancos britânicos, Gough e Flanders (2009) verificaram que esses homens experimentaram julgamentos negativos frequentes por homólogos homossexuais e outros homens heterossexuais sobre seu peso, e essas experiências afetaram sua autoestima, socialização e saúde mental. No entanto, ser parte da comunidade ursina melhorou sua autoaceitação e qualidade de vida. Isso parece estar associado às mudanças sociais em relação à diversidade nas sociedades ocidentais. O mesmo não parece ser verificado em algumas sociedades orientais, conforme descrito no próximo estudo.

Até esta data, o único estudo sobre homens homossexuais ursos na China foi publicado em 2014 (Lin, 2014). De uma amostra de 217 participantes, 12 deles, cuja idade média era de 27 anos, foram selecionados aleatoriamente para um estudo qualitativo sobre sua identidade como gays ursos. De acordo com este estudo, ser um gay urso na China era representado por gêneros binários (masculinidade mais valorizada do que feminilidade), dualismo sobre o tipo de corpo (corpo ectomorfo mais valorizado do que um corpo endomorfo) e influenciado pela pressão dos pares para se adequar a uma estética estereotipada para ser parte da comunidade ursina que parece semelhante aos estereótipos dos gays ursos das sociedades ocidentais. No entanto, concluiu-se que a comunidade de ursos chineses não era diversificada e tão inclusiva como nas sociedades ocidentais e que, apesar de evitar o estereótipo heterossexual, esta era a prática concreta interpessoal e subjetiva desejada e idealizada pelos participantes. $O$ mesmo pôde ser identificado em alguns outros estudos apresentados nesta revisão. Para os gays ursos, seu peso corporal é frequentemente associado à identificação com a comunidade ursina e autoaceitação, conforme demonstrado no estudo de Lyons e Hosking (2014).

Em uma pesquisa transversal quantitativa feita pela internet, Lyons e Hosking (2014) investigaram a saúde física, mental e sexual de 93 homens gays autoidentificados como Cubs (ursos mais jovens) na Austrália, cuja idade média era de 26 anos. Os autores verificaram que quanto maior o peso corporal, menor a autoestima. No entanto, ao contrário de outros estudos, eles verificaram que uma menor autoestima não previu uma diminuição de frequência de relacionamentos românticos e de autocuidado sexual (por exemplo, submetendo-se a testes para verificar doenças sexualmente trasnmissíveis). Nesse caso, a identificação ao grupo tornou-se um fator protetor para muitas dimensões da saúde desses jovens. Resultados semelhantes foram encontrados em estudos brasileiros descritos a seguir.

Em um estudo de Cerqueira e Souza (2015), 19 participantes brasileiros de um centro urbano da região Sudeste, com idade variando entre 22 e 38 anos, foram entrevistados sobre seus discursos e práticas em torno de seus autoconceitos como ursos e o uso de seus corpos. Segundo os discursos dos participantes, houve uma convergência sobre um modelo de identidade que rematia ao que era transmitido pela mídia e que se materializava na representação do "urso musculoso": um homem branco (mas, às vezes, etnicamente misturado) parrudo e peludo, barbudo, musculoso, masculino, de meia-idade. Entre os participantes, tal representação só era aceita se fosse diametralmente oposta ao estereótipo ectormórfico, suave, magro e feminizado propagado na cultura gay geral, e se fosse fisicamente grande o suficiente para não ser confundido com $\circ$ estereótipo de corpo tonalizado, liso, finos e musculoso - chamado, no contexto da comunidade ursina do Sudeste do Brasil, de "bicha pão-com-ovo" e "Barbie" (equivalente ao "clone" norte-americano), respectivamente. Este estudo concluiu 
que a subjetividade do gay urso, para esta amostra, era permeada por múltiplos e variados discursos e conceitos que, em última instância, derivaram e foram executadoss de acordo com a perspectiva da masculinidade hegemônica.

Outro estudo com uma amostra brasileira foi feito por Domingos (2015). O autor publicou sua dissertação sobre a construção da identidade do gay urso, analisando o discurso de um grupo de homens que assim se identificaram de um centro urbano do Nordeste. Embora suas análises tenham se baseasdo em perfis publicados de sites da internet para gays ursos, ele verificou que, de forma semelhante ao estudo de Cerqueira e Souza (2015), a representação sobre pertencer a esta comunidade começou a partir do momento que esses homens se perceberam marginalizados na cultura gay geral, enquanto esta se polarizava entre os estereótipos da "bicha" e da "Barbie", sendo permeada pela ideal de se tornarem indivíduos sexualmente desejáveis, apesar de terem corpos que não se encaixavam no contexto cultural gay predominante. Como tal, o corpo de um urso deveria ser marcado por ícones e narrativas como aquelas descritas pela amostra do Sudeste do Brasil.

Santos e Lago (2016) realizaram um estudo sobre o homoerismo entre os idosos que frequentavam um bar dedicado à comunidade dos ursos em um centro urbano localizado na região sul do Brasil. De acordo com suas observações, o significado de pertencer à comunidade ursina era fomentado por este ambiente e parece ter permitido a esses indivíduos a subjetivação de suas experiências através da expressão de seu homoerismo e identificação com múltiplas combinações de identidades (urso, não urso, jovem, maduros ou nenhuma). Este foi um dos poucos estudos que descreveu como um ambiente se tornou um locus para a subjetivação das práticas dos seus atores sociais, onde uma inclusão diversificada de indivíduos associou-se à expressão do homoerotismo. Em contraste, muitos outros estudos ilustraram o foco na geometria do corpo e na dinâmica da exclusão.

Por exemplo, Benavides-Meriño (2016) realizram um estudo sobre como os gays ursos chilenos conceitualizaram suas masculinidades. Os participantes deste estudo viviam em uma grande área urbana do Chile e tinham uma idade média de 26 anos. $O$ autor verificou que a identidade ursina de seus participantes estava associada à referência de ser, acima de tudo, masculino, como camuflagem social, o que lhes permitiria navegar em espaços heterossexuais sem serem marginalizados como homens gays - fenômeno também verificado por Manley, Levitt e Mosher (2007) com participantes americanos e Lin (2014) entre participantes chineses. Na mesma linha, com - fortalecimento do sentimento de pertença, essa identidade também aumentou as chances de encontrar parceiros sexuais. $O$ estudo concluiu que, entre os gays ursos chilenos, o significado de fazer parte da comunidade de ursos estava associado à expressão de virilidade, à competição pelo capital sexual e à socialização segmentada e autodiscriminatória por meio da rejeição de formas de expressão feminilizadas - o autor até sugeriu que as atribuições de seus participantes eram influenciadas pela homofobia internalizada.

McGrady (2016) analisou a história da vida de 21 homens gays ursos, com média de 40 anos de idade, dos Estados Unidos do Sul, Centro-Oeste e Oeste. Ele investigou como esses homens resistiram aos estigmas relacionados ao sobrepeso e por ser um urso. Esta análise baseou-se em tópicos relacionados às experiências de saída do armário de seus participantes, sua masculinidade, suas percepções e suas experiências sobre seus corpos (ursinos), bem como sua participação na comunidade de ursos e suas experiências de vida antes e depois de participar dessa comunidade. $O$ autor verificou que, com base nas narrativas de seus participantes, a resistência contra esses estigmas foi operada pela inserção nos grupos sociais dos ursos. Participar desses grupos legitimou o erotismo de seus corpos e desafiou os estereótipos de excesso de peso.

De acordo com os estudos de outros indicados nesta revisão, McGrady (2016) também verificou que, apesar de ser parte da comunidade de ursos ou identificar-se como parte deste grupo, não houve necessariamente um enfraquecimento dos sentimentos de marginalização em relação aos seus corpos e orientação sexual. Essa perspectiva pareceu reforçar as preocupações dos participantes em gerenciar sua masculinidade e sua apresentação ursina para evitar uma avaliação negativa dos seus pares. Curiosamente, este estudo destacou a subjetividade ambivalente que parece permear a autopercepção dos ursos, sua identidade e a forma como navegam no seu contexto sócio-cultural: por exemplo, de um lado, ter um corpo de urso e uma 
atitude masculina não implicaram necessariamente em um sentimento de necessidade de pertencer a este grupo, nem de ter uma inclinação homoerótica exclusiva em relação aos homens homossexuais. $O$ indivíduo pode ser atraído por homens não ursos e não masculinos também. Por outro lado, ao procurer evitar a marginalização, alguns indivíduos são induzidos a modelar seus comportamentos a partir de atributos heteronormativos (por exemplo, antiefeminação) e da cultura gay geral (por exemplo, foco na juventude e aparência).

Conforme visto nos estudos citados, parte da constituição da subjetividade do homem gay urso pareceu ser influenciada pela da ideologia sexual hegemônica. Evitar o ônus desta ideologia pode ter sido um dos fatores de pressão para a formação da comunidade ursina ou para a identificação com a "geometria" ursina a fim de enfrentar a heteronormatividade social e buscar aceitação, sentimento de pertença e afirmação de seu homoerotismo apesar de sua idade, biometria e formas de expressão de seu desejo. Embora esses elementos pareçam positivos para o movimento dos ursos, alguns estudos indicaram que indivíduos dessa comunidade parecem ser afetados pelos mesmos fatores psicossociais que afetam a saúde sexual e mental de outros indivíduos da comunidade gay.

Por exemplo, Willoughby et al. (2008) verificaram em sua amostra americana e canadense que seus participantes ursos eram mais propensos a ter relações sexuais com penetração anal sem preservativo do que outros homens da comunidade gay em geral. Em outro estudo, Moskowitz et al. (2013) realizaram uma investigação em larga escala de 469 homens homossexuais da Austrália, Canadá, Nova Zelândia, Reino Unido e Estados Unidos sobre seus traços físicos, comportamentais e psicológicos. Eles descobriram que seus participantes estavam de acordo com os identificadores físicos associados aos membros da comunidade ursina, mas eram impactados pela cultura gay geral ao ponto em que se sentiam menos atraentes e apresentavam menor autoestima. De acordo com este estudo, parece que esse impacto influenciou os comportamentos sexuais de seus participantes, no sentido de que eles eram mais propensos a se engajar em práticas sexuais, sobretudo em comportamentos sexuais atípicos, como o anilingus, fisting e voyeurismo com mais frequência quando em comparação com homens não ursos.
Quidley-Rodriguez \& Santis (2016) revisaram onze estudos sobre a saúde dos homens gays que se autoidentificaram como ursos. Eles concluíram que estes homens estavam mais inclinados a desenvolver problemas de peso, apresentar menor autoestima, bem como se expor a comportamentos sexuais de risco mais frequentemente do que outros homens gays. Em um estudo de uma grande amostra de Toronto (Noor, et al., 2017) formada por diferentes nichos da comunidade gay, verificou-se que aqueles identificados como Bear/Leather/BDSM (bondagem, disciplina, dominação, submissão, sadismo e masoquismo) apresentaram maior autoestima sexual, e eram mais propensos a relatar ter feito sexo anal sem camisinha com parceiros casuais em comparação com outros grupos. Embora esta informação tenha revelado fatores importantes das práticas psicossociais desses indivíduos, foi parcialmente congruente com outros estudos indicados nesta revisão. No entanto, não ficou claro se esses fatores foram igualmente contabilizados entre os indivíduos Bears, Leather e BDSM, uma vez que estudos sobre comportamentos sexuais entre Leathermen indicaram maior incidência de infecção pelo HIV em comparação com outras subculturas (Moskowitz et al., 2011 ).

Finalmente, Schnarrs et al. (2017) realizaram um estudo com uma grande amostra de gays ursos e verificaram que, comparando os resultados entre eles, os participantes indicaram ser menos propensos a usar preservativos durante o sexo. Os autores especularam que esse fenômeno ocorria porque fazer sexo sem preservativo era percebido como comportamento congruente com os valores normativos da comunidade de ursos, associados à pressão dos pares e à busca pela aceitação, ou devido ao aumento da desejabilidade homoerótica. Ambos os elementos pareciam estar ligados à masculinidade hegemônica que permeia a subjetividade dos homens gays autoidentificados como ursos, indicando que esse elemento subjetivo poderia influenciar a saúde sexual desses indivíduos.

Ao discutir sobre o indivíduo moderno, é aceito que estse faça parte de um contexto em que seu corpo é usado como dispositivo de controle da população, legitimado por práticas científicas, visando o bemestar e a segurança dos indivíduos. Isso significa que se assume que 0 indivíduo tem um corpo que precisa de regulação, porque o mesmo apresenta vulnerabilidades inerentes que podem afetar esse 
principal objetivo social. Nesse sentido, não é uma surpresa que o elemento essencial da identificação entre os gays ursos se concentre em seus corpos. Além disso, é através de seus corpos que eles expressam sua masculinidade, como esperado para todos os homens de suas respectivas culturas. Conforme observado nesta revisão da literatura, o corpo, a masculinidade, o homoerismo e a homoafetividade compõem a equação que produzirá o fenômeno da identidade do urso, de acordo com sua variação histórica e geográfica.

Outrossim, essa perspectiva implica que a identidade do urso está mais associada a uma disposição da sexualidade e sua expressão múltipla do que a uma micro ideologia de atitudes que, nesse contexto, comporiam suas narrativas sobre seu eu. A sexualidade do urso é expressa através de uma performance deste eu, que nunca é completa, porque é antes uma polissemia de práticas subjetivas múltiplas e idiossincráticas. No entanto, suas expressões parecem convergir para a busca de um sentimento de pertença.

Este é o caso, provavelmente, porque a pertença é baseada na distribuição de atributos relevantes reconhecidos entre os membros de um grupo específico que informa sobre as características de uma pessoa e as diferencia de outras, formando grupos de pares associados a uma imagem e sua reputação. $A$ experiência objetiva e subjetiva de pertencer a esses grupos de pares também funciona como plataforma ou como dispositivo de agrupamento do qual os indivíduos aumentariam a probabilidade de serem escolhidos por outros com base em seus atributos (Peacock, Eyre, Quinn e Kegeles, 2001, Bénabou \& Tirole, 2006). Como tal, ser um membro da comunidade de ursos, obviamente, implicaria alguns ganhos, como o possível aumento da autoestima, fortalecimento da identidade, erotização e desejabilidade, e maior possibilidade de encontrar um parceiro ou "fica", "uma transa" e, eventualmente, desenvolver relacionamentos românticos.

No entanto, o preço da recuperação da "masculinidade natural" preconizada pela comunidade ursina vem à custa da experiência de ser marginalizada entre os marginalizados, a experiência de conflitos de expressão de gênero, a pressão para se adequar aos sinais que justificam a pertença a este grupo, e - risco de sustentar e naturalizar uma narrativa e prática heteronormativa. Finalmente, parece que, mesmo dentro da subcultura ursina, há uma crescente pressão dos pares que influencia a compartimentação de tipos - que pressupõem um modelo de referência a partir do qual outras variâncias devem ser seguidas, de acordo com a assimilação cultural desse modelo.

Essa pressão para a variação é o núcleo da formação da comunidade dos ursos, conforme discutido na revisão histórica apresentada. No entanto, parece continuar a existir. Por exemplo, enquanto narrativas e práticas de gays ursos procuram minimizar as diferenças entre "ser um gay urso" e "ser heterosexualmente masculino", uma vez que a maioria executa um conjunto específico de comportamentos identificatórios, tais comportamentos são naturalizados e esperados que assim sejam operados (Stets \& Burke, 2000). Se alguém estiver em conformidade com essa expectativa, os reforçadores associados à estima do grupo serão mais fortes e, consequentemente, aqueles que demonstram que as expectativas do grupo foram atendidas serão considerados como "melhores", "mais desejáveis" e "modelos" a serem seguidos. Caso contrário, esses "modelos" estarão propensos a desencorajar os comportamentos que se desviem das expectativas e solicitarão a esses outros que busquem outras afiliações (Abrams \& Hoog, 1998). Isso poderia explicar as narrativas de alguns indivíduos ursos sobre a alusão a um confronto entre os ursos musculosos e os ursos gordos ou entre homens masculinos e os mais femininos dentro da comunidade ursina hoje em dia? Estudos futuros poderão esclarecer esse novo fenômeno.

No entanto, certamente explica a variabilidade de tipos e práticas dentro dessa comunidade. Neste ponto da história, a subjetividade do homen gay urso parece ser constituída por premissas iniciais que fundaram o movimento dos ursos, variando não apenas em relação aos contextos socioculturais, mas também em seus próprios grupos de indivíduos, onde essas premissas são fluidas e até ambivalentes. Não obstante, o denominador comum dessa dinâmica de poder é a idéia de que os corpos feminizados (e suas expressões) são percebidos como tendo um status menor - o que implica que pode haver um esforço coletivo para legitimar sua reputação masculina reconhecida como parte da normatividade.

\section{Considerações finais}

Este artigo articulou elementos que enfatizaram a importância da competencia cultural quando se 
aborda o fenômeno da identidade dos homens gays ursos e suas expressões, especialmente quando uma relação de ajuda é a configuração da interlocução. Nesse sentido, o denominador comum desse fenômeno - masculinidade - deve ser ponderada como uma problematização que vai além do determinismo biológico e cultural. Conforme discutido, muitos homens gays ursos podem estar em risco de serem acometidos por doenças sexualmente transmissíveis e disseminá-las devido à pressão dos pares, o que parece ser sustentado por representações sociais sobre o que significa ser um homem gay urso em diferentes contextos socioculturais, e isso é alarmante. Portanto, profissionais de saúde mental, educadores e influenciadores poderiam se beneficiar com a compreensão das especificidades das necessidades dessa população.

A literatura publicada na última década explorou que os membros da comunidade ursina apresentaram um autoconceito geral que implicava a integração de uma masculinidade hegemônica baseada em premissas da heteronormatividade que rejeita a efeminidade nos homens e, ao mesmo tempo, forma um grupo que enfatiza comportamentos afetivos. Se isso for verdade, os homens gays ursos apresentariam evidências de heterossexismo internalizado, atitudes negativas em relação à efeminidade e, ao mesmo tempo, apresentariam uma ausência ou baixa evidência de homonegatividade internalizada.

Portanto, também se poderia hipotetizar que eles seriam menos afetados pelo estresse minoritário do que outros homens gays que não se identificam como ursos. No entanto, a informação coletada pela amostra da literatura da última década publicada pareceu indicar que os ursos foram submetidos à pressão coletiva dos pares para se conformarem com uma masculinidade hegemônica, gerando uma migração para subnichos dentro da comunidade ursina, vinsando um aumento da desejabilidade, e sustentando uma subjetividade ambivalente quando os atributos negativos associados à efeminidade são questionados.

Nesta perspectiva, estudos adicionais são sugeridos para verificar empiricamente $\circ$ impacto da masculinidade hegemônica e do assédio heterosexista entre os homens gays ursos, avaliando como esse impacto pode estar associado a atitudes negativas em relação à efeminidade, bem como entre bissexuais e outros homens que fazem sexo com homens que se identificam como ursos e homens gays não ursos, de diferentes contextos sócio-econômico-culturais e étnicos, usando amostras representativas, visto que a maioria dos estudos apresentados nesta revisão foi focada em indivíduos brancos anglo-saxões, cuja média de idade era de 35 anos de idade. Outros elementos de tais associações empíricas podem ressaltar peculiaridades da experiência de ser um homen gay urso, suas necessidades psicossociais e como as práticas afirmativas de saúde mental podem ser adequadas para responder as necessidades desses indivíduos.

\section{Referências}

Abrams, D., \& Hogg, M.A. (1988). Comments on the motivation status of self-esteem in social identity and intergroup discrimination. European Journal of Social Psychology, 18(4), 317-334. Recuperado de http://onlinelibrary.wiley.com/doi/10.1002/ ejsp.2420180403/abstract. doi:10.1002/ eisp. 2420180403

Bastos, S. P. (1997). O Estado Novo e os seus vadios: contribuição para o estudo das identidades marginais e da sua repressão. Lisboa: Dom Quixote.

Bénabou, R., \& Tirole, J. (2006). Incentives and prosocial behaviour. American Economic Review, 96(5), 16521678. Recuperado de https://www.aeaweb.org/ articles?id=10.1257/aer.96.5.1652. doi: $10.1257 /$ aer.96.5.1652

Berlinck, M. T. (2010). A noção de subjetividade na psicopatologia fundamental. Revista Latinoamericana de Psicopatologia Fundamental, 13(4), 551 557. Recuperado de http://www.scielo.br/ pdf/rlpf/v13n4/01.pdf. doi: 10.1590/S141547142010000400001

Bottero, J. (2001). Everyday Life in Ancient Mesopotamia. Baltimore: The Johns Hopkins University Press.

Carter, D. (2004). Stonewall: The Riots that Sparked the Gay Revolution. New York: St. Martin's Press.

Chauncey, G. (1994). Gay New York: Gender, Urban Culture, and the Making of the Gay Male World, 1890-1940. New York: Basic Books.

Colligan, C. (2003). A race of born pederasts: Sir Richard Burton, homosexuality, and the Arabs. Nineteenth-Century Contexts, 25(1), 1-20. Recuperado de http://www.tandfonline.com/doi/ abs/10.1080/0890549032000069131. doi: $10.1080 / 0890549032000069131$ 
Costa, J. F. (1992). A inocência e o vício: estudos sobre o homoerotismo. Rio de Janeiro: Relume- Dumará.

Dall'Orto, G. (2015). Tutta un'altra storia: L'omosessualità dall'antichità al secondo dopoguerra. Milano: il Saggiatore.

Domingos, J.J. (2015). O discurso dos ursos: outro modo de ser da homoafetividade. João Pessoa: Marca da Fantasia.

Edsall, N.C. (2003). Toward stonewall: Homosexuality and society in the Modern Western World. Richmond, VA: University of Virginia Press

Eldahan, A. I., Pachankis, J. E., Rendina, H. J., Ventuneac, A., Grov, C., \& Parsons, J. T. (2016). Daily minority stress and affect among gay and bisexual men: a 30-day diary study. Journal of Affective Disorders, 190, 828835. Recuperado de https://www.ncbi.nlm.nih.gov/ pubmed/26625095. doi: 10.1016/i.jad.2015.10.066

El-Rouayheb, K. (2005). Before Homosexuality on ArabicIslamic World: 1500-1800. Chicago: Chicago University Press.

Foucault, M. (1976). Histoire de la Sexualité I. La volonté de savoir. Paris: Gallimard.

Foucault, M. (1984). Histoire de la Sexualité II. L'usage des plaisirs. Paris: Gallimard.

George, A. (1999). The Epic of Gilgamesh. New York: Penguin Books.

Giddens, A. (1993). A transformação da intimidade. São Paulo: UNESP.

Gough, B., \& Flanders, G. (2009). Celebrating "obese" bodies: gay "bears" talk about weight, body image and health. International Journal of Men's Health, 8, 235-253. Recuperado de http://www.mensstudies. info/OJS/index.php/IJMH/article/view/579. doi:10.3149/imh.0803.235

Guattari, F. (1999). Da produção de subjetividade. In Parente, A. (Org.), Imagem máquina: A era das tecnologias do virtual (pp.177-191). Rio de Janeiro: Ed. 34.

Hatzenbuehler, M. L. (2009). How does sexual minority stigma "get under the skin"? A psychological mediation framework. Psychological Bulletin, 135(5), 707 730. Recuperado de https://www.ncbi.nlm.nih.gov/ pubmed/19702379. doi: 10.1037/a0016441

Hennen, P. (2005). Bear bodies, bear masculinity: Recuperation, resistance, or retreat? Gender and Society, 19(1), 25-43. Recuperado de http://journals.sagepub. $\mathrm{com} /$ doi/pdf/10.1177/0891 243204269408. doi: $10.1177 / 0891243204269408$
Hinsch, B. (2005). Van Gulik's sexual life in Ancient China and the matter of homosexuality. NAN NU - Men, Women \& Gender in Early \& Imperial China, 7(1), 79-91.

Hoffschildt, R. (1999). Die Verfolgung der Homosexuellen in der NS-Zeit. Zahlen und Schicksale aus Norddeutschland. Berlin: Rosa Winkel.

Hubbard, T. K. (2003). Homosexuality in Greece and Rome: A sourcebook of basic documents. Berkeley: University of California Press.

Kinsman, G. (1996). The Regulation of Desire: Homo and Hetero Sexualities. Montreal: Black Rose Books.

Santos, D. K., \& Lago, M. C. S. (2016). Heterotopias of (un) desirable bodies: homoeroticism, old age and other dissidences. Vibrant - Virtual Brazilian Anthropology, 13(1), 115-131. Recuperado de http://www.scielo. $\mathrm{br} / \mathrm{pdf} / \mathrm{vb} / \mathrm{v} 13 \mathrm{nl} / 1809-4341$-vb-13-01-001 15.pdf. doi: $10.1590 / 1809-43412016 v 13 n 1 p 115$

Lin, C. (2014). Chinese gay bear men. Culture, Society \& Masculinities, 6 (2), 183-193. Recuperado de http:// www.mensstudies.info/OJS/index.php/CSM/article/ view/690/pdf_4

Lyons, A., \& Hosking, W. (2014). Health disparities among common subcultural identities of young gay men: physical, mental, and sexual health. Archives of Sexual Behavior, 43(8), 1621-1635. Recuperado de https:// www.ncbi.nlm.nih.gov/pubmed/250601 21. doi: 10.1007/s10508-014-0315-1

Manley, E., Levitt, H., \& Mosher, C. (2007). Understand the bear movement in gay male culture: Redefining masculinity. Journal of Homosexuality, 53(4), 89-112. Recuperado de https://www. ncbi.nlm.nih.gov/pubmed/18689193. doi: $10.1080 / 00918360802103365$

Maspero, H. (1965). La Chine Antique. Paris: PUF.

Meyer, I. H. (2003). Prejudice, social stress, and mental health in Lesbian, Gay, and Bisexual populations: conceptual issues and research evidence. Psychological Bulletin, 129(5), 674-697. Recuperado de https://www. ncbi.nlm.nih.gov/pmc/articles/PMC2072932/. doi: 10.1037/0033-2909.129.5.674

Montserrat, D. (1996). Sex and Society in Graeco-Roman Egypt. London: Kegan Paul International.

Moskowitz, D. A., Seal, D.W., Rintamaki, L., \& Rieger, G. (2011). HIV in the leather community: Rates and riskrelated behaviors. AIDS and Behavior, 15(3), 557-564. Recuperado de https://www.ncbi.nlm.nih.gov/pmc/ articles/PMC4082977/. doi: 10.1007/s10461-0099636-9 
Moskowitz, D. A., Turrubiates, J., Lozano, H., \& Hajek, C. (2013). Physical, behavioral, and psychological traits of gay men identifying as Bears. Archives of Sexual Behavior, 42(5), 775-784. Recuperado de https:// www.ncbi.nlm.nih.gov/pubmed/23613138. doi: $10.1007 / \mathrm{s} 10508-013-0095-\mathrm{z}$

Mott, L. (201 1). Etno-história da homossexualidade na América Latina. Recuperado de https://wp.ufpel.edu. $\mathrm{br} / \mathrm{ndh} /$ files/2017/02/04.-Luiz_Mott.pdf

Murstein, B. (1974). Amor, sexo e casamento através dos tempos. Rio de Janeiro: Artenova.

Noor, S.W., Adam, B.D., Brennan, D.J., Moskowitz, D.A., Gardner, S., Hart, T.A. (2017). Scenes as MicroCultures: Examining Heterogeneity of HIV Risk Behavior Among Gay, Bisexual, and Other Men Who Have Sex with Men in Toronto, Canada. Archives of Sexual Behavior, 47(1), 309-321. Recuperado de https://www.ncbi.nlm.nih.gov/pubmed/28429157. doi: $10.1007 / \mathrm{s} 10508-017-0948-y$

Parkinson, R. B. (1995). 'Homosexual' desire and middle kingdom literature. The Journal of Egyptian Archaeology, 81(1), 57-76. Recuperado de http://journals.sagepub.com/doi/ abs/10.1177/030751339508100111

Pattanaik, D. (2002). The Man who was a Woman and other Queer Tales from Hindu Lore. New York: Harworth Press.

Peacock, B., Eyre, S. L., Quinn, S. C., \& Kegeles, S. (2001). Delineating differences: sub-communities in the San Francisco gay community. Culture, Health \& Sexuality, 3(2), 183-201. Recuperado de http://www.tandfonline.com/doi/ abs/10.1080/136910501750153003. doi: 136910501750153003

Pretzel, A., \& Rossbach, G. (2000). Wegen der zu erwartenden hohen Strafe... Homosexuellenverfolgung in Berlin 1933-1945. Berlin: Rosa Winkel.

Quidley-Rodriguez, N., \& de Santis, J.P. (2016). Physical, Psychosocial, and Social health of Men who identify as Bears: A Systematic Review. Journal of Clinical Nursing, 25(23-24), 3484-3496. Recuperado de https://www. ncbi.nlm.nih.gov/pubmed/27174226. doi: 10.1111/ jocn. 13368

Ranke-Heinemann, U. (1991). Eunuchs for the Kingdom of Heaven: Women, Sexuality, and the Catholic Church. New York: Penguin Books.

Rubin, G. (2004). S/M's the catacombs: a temple of the butthole. In: Thompson, M. (Ed.). Leatherfolk: Radical Sex, People, Politics, and Practice (pp. 119-1 40). Los Angeles: Daedalus Publishing.
Sáez, J. (2005). Excesos de la masculinidad: la cultura leather y la cultura de los osos. In: Bachiller, C. S., Dauder, S. G., \& Martínez, C. B. (Eds.). El Eje del Mal es Heterosexual. Figuraciones, Movimientos y Prácticas Feministas Queer (pp. 137-149). Madrid: Traficantes de Sueños.

Schnarrs, P. W., Rosenberger, J. G., Schick, V., Delgado, A., Briggs, L., Dodge, B. \& Reece, M. (2017). Difference in Condom Use between Bear Concordant and Discordant Dyads during the Last Anal Sex Event. Journal of Homosexuality, 64(2), 195-208. Recuperado de http://www.tandfonline.com/doi/ full/10.1080/00918369.2016.1174024. doi: $10.1080 / 00918369.2016 .1174024$

Suresha, R. (2002). Bears on Bears: Interviews \& Discussions. Los Angeles: Alyson Publications.

Stets, J.E., \& Burke, P.J. (2000). Identity theory and social identity theory. Social Psychology Quarterly, 63(3), 224-237. Recuperado de https://www.jstor.org/ stable $/ 2695870$ ?seq=1 \#page_scan_tab_contents. doi: $10.2307 / 2695870$

Tamagne, F. (2000). Histoire de l'Homosexualité en Europe: Berlin, Londres, Paris: 1919-1939. Paris: Seuil.

Tulloch, T. G., Rotondi, N. K., Ing, S., Myers, T., Calzavara, L. M., Loufty, M. R., \& Hart, T. A. (2015). Retrospective reports and developmental stressors, syndemics, and their association with sexual risk outcomes among gay men. Archives of Sexual Behaviour, 44 (7), 1879-89. Recuperado de https://www.ncbi.nlm.nih.gov/pmc/ articles/PMC4559573/. doi: 10.1007/s10508-015$\underline{0479-3}$

Vanita, R., \& Kidwai, S. (2000). Same-Sex Love in India: Readings from Literature and History. New York: St. Martin's Press.

Vygotsky, L.S. (1929/2000). Lev S.Vigostski: Manuscrito de 1929. Educação \& Sociedade, 71, 21-44. Recuperado de http://www.scielo.br/pdf/es/v21n71/a02v2171. pdf

Willoughby, B. L., Lai, B. S., Doty, N. D., Mackey, E. R., \& Malik, N. M. (2008). Peer crowd affiliations of adult gay men: linkages with health risk behaviors. Psychology of Men \& Masculinity, 9 (4), 235-247. Recuperado de http://psycnet.apa.org/record/2008-14695-004. doi: $10.1037 / 1524-9220.9 .4 .235$

Wright, L. (1997). The Bear Book: Readings in the History and Evolution of a Gay Male Subculture. Binghamton: The Haworth Press. 